\title{
How Espoused Culture Influences Misuse Intention: A Micro-Institutional Theory Perspective
}

\author{
Anat Hovav \\ Korea University Business School \\ anatzh@korea.ac.kr
}

\begin{abstract}
Following Willson and Warkentin's [42] call for understanding the interaction between employees and the organization in the context of computer abuse, this paper investigates the effect of espoused institutional pressure on misuse intention in South Korea. In addition, we hypothesize the effect of culture in the form of self-construal, power distance and Confucian dynamism on users' perceptions of organizational coercive, normative and mimetic pressures. We collected 232 usable surveys. Since the sample was mostly a convenience sample, the response rate was close to a 100\%. Our analysis found that coercive pressure has no effect on misuse intention, while normative pressures has significant deterring effect and mimetic has significant motivating effect on misuse intention. As to culture, self-construal had the strongest effect on institutional pressure and subsequently on misuse intention.
\end{abstract}

\section{Introduction}

Research addressing behavioral information security was mostly conducted in the U.S. or Western Europe (e.g., [5], [17], [36], [41]). As businesses globalize and employ people from different cultures, it is imperative that we understand how cultural differences may affect users' security-related behavior. Studies have suggested that national culture influences the development, adoption, use, and management of organizational information systems (IS) [4]. Cultural differences are likely to have an increase affect in countries where cultural norms supersede organizational structure. Studies have also suggested that country-level culture may have a differential effect on IS misuse behavior [14]. In addition, most current studies examine users' rationality, cognition or characteristics. For example, several studies adopted a utilitarian approach for deterring misuse behavior (e.g., [10], [41]). This is because many misuse studies are rooted in deterrence theory (e.g., [5], [17]). The key assumption is that behavior is driven by a rational decision process based on costs and benefits of the act to the focal actor. Other studies used protection motivation theory (PMT) and reactance theory (RT) as determinants to users' compliance with organizational information security policies (ISP) (e.g., [12], [18], [19]). PMT departure point assumes individual's desire to protect oneself and the organization, while RT assumes that users are likely to comply with security policies they perceive as justifiable (e.g., [16], [24]). Despite this increasing body of research, there is a lack of research that aim to understand how organizational environment influences misuse behavior. This paper answers recent calls by behavioral security scholars to better understand the interaction of employees with the organization in the context of computer abuse [for example see 42]. The intersection of cultural attributes and organizational environment is especially interesting in cultures where normative conditions (social standing, normative pressure), social or mimetic pressures (peer behavior, face, appearances) and collective memory (the past determines future actions) are more important in shaping ones behavior than individual perceptions of cost-benefit. For example, the opinions of one's social network have a strong influence in East Asian cultures and thus the threat of embarrassment stemming from the discovery of IS misuse may make the perceived certainty of organizational sanctions a more salient concern than the severity of punishment. In addition, group harmony supersedes individual needs. Actions that appear unethical to Westerners are fully justified in Asian cultures if they prevent conflict and discord. In Korea, social status is likely to have an impact on misuse behavior (saving a manager's face), which depends on who is requesting the illicit act. Furthermore, while the "rational actor" makes decisions based on a costbenefit analysis and utility maximization, the institutional model views decision making as a social process where individuals accept and follow social norms [38]. 
Against this backdrop, our study uses microinstitutional pressures (coercive, normative and mimetic) to examine motivators and inhibitors of IS misuse in Korea. We chose Korea for the following reasons: First, Korea exhibits high levels of vertical collectivism [34]. Therefore, we expect normative pressure to have a strong influence on users in Korea. Second, Korea is typified by high powerdistance (PD). Therefore, we expect that coercive and vertical mimetic pressures will have an influence on users' misuse behavior. Third, Korea's culture is driven by strong tradition, which emphasizes the need to prepare for the future (central to Confucian dynamism, LTO). Given the collectivistic and normative nature of Asian culture, we propose the effectiveness of using the institutional model as a lens for our investigation. This study proposes a model that combines coercive, normative, and mimetic determinants of IS misuse behavior along with three cultural characteristics (selfconstrual, power distance and long-term orientation). Our objectives are to explore: (1) the effect of organizational espoused institutional pressure on misuse behavior and (2) the determinant effect of individual cultural characteristics on these espoused institutional pressures.

\section{Literature review}

\subsection{Institutional theory}

Institutional theory is based on the assumption that an institutional environment influences the performance of organizations. Institutionalization is the process in which obligations or rules are formed based on social thought and actions [26]. Institutionalization is defined as the process that occurs when organizations accept the effect of their institutional environment such as social value, norms, and beliefs. Institutional pressure suggests that organizations tend to imitate other organizations in the environment when goals and technical effects are uncertain. Institutional isomorphism refers to the adaption of accepted social norms and a value system by organizations [26]. DiMaggio and Powell [7] defined three types of isomorphism: coercive, normative, and mimetic. Coercive isomorphism describes organizations that adopt certain norms due to external authoritative pressures such as governmental policy or regulatory activity, or driven by market forces or competition [38]. Normative isomorphism often occurs as a result of punditries (professionalization). Pundits could influence organizations by providing professional opinions or controlling the work conditions and methods in an industry. ${ }^{1}$ Mimetic isomorphism often occurs in uncertain times, particularly when there is little understanding of a new process, technology or external conditions. As a result, companies imitate organizations that appear to have adopted a successful model [7]. Most researchers have studied institutional influences at the organizational level. However, institutional pressures could also affect individual behavior. Several authors suggested the need for micro-institutionalization research (e.g., [2]). These researchers posit that the assumption that institutions are self-standing entities is an over simplification of reality. Organizations are composed of people that over time develop common goals, norms and rules. Neoinstitutional theory "forgot" about the individuals that enact institutions ([2]). Therefore, "there is still an absence of understanding how individuals subjectively interpret institutional pressures to cognitively generate alternatives" ([2]: p. 4). Recent studies examined the influence of coercive pressure at the individual level [11] and the group level [23]. In IS research, Phang and Kankanhalli [30] identified the presence of mimetic, normative, and coercive pressures at the individual level and posited that early adopters may create institutional pressures on late adopters. Marett, Otondo and Taylor [25] examined the influence of coercive, normative and mimetic influence on the use of bypass systems by long-haul truck drivers. Dash, Bhusan, and Samal [6] examined the influence of mimetic forces on customers' attitude towards mobile banking in India.

Normative pressures stem from individual's espoused beliefs regarding their environment [22]. These organizational espoused beliefs can influence individual users' behavior towards technology adoption [22]. Coercive pressure means that individuals are pressured by their organizations. Since the organization legal system is conveyed to members though culture values, organizational environment reflects organizational culture [31]. Thus, individuals who are members of an organization are expected to follow this culture as they would follow the law. Furthermore, from an organizational perspective, security policies rely on the same underlying deterrent mechanism as societal laws [5]. Therefore, formal sanctions in the form of punishment and informal sanctions in the form of peer disapproval can be perceived as coercive pressure. Mimetic pressures were found to shape the opinion of early adopters [31] and the continued use of innovative technology [25]. In this study, we posit that organizational coercive, normative and mimetic effects can be adapted to the

\footnotetext{
${ }^{1}$ An example is the case when a leading consulting company endorses a product, which later becomes a de facto industry standard.
} 
individual level in the context of misuse behavior. Individuals are likely to be influence by policies, follow norms and imitate.

\subsection{Espoused national culture}

We selected three cultural dimensions as determinants for coercive, normative and mimetic pressures. As discussed, the three cultural dimensions, PD, collectivism and LTO, are unique to Asian cultures and differ from the West. These three dimensions also affect the way individuals regard organizational and institutional pressure. For example, in Korea, people regard their work as a kind of "another family." Among the OECD nations, Koreans spend more hours at work than most developed countries [27]. Supervisors feel paternal responsibilities towards their subordinates. Although Hofstede's cultural dimensions are often used at the country level, we measured these dimensions at the individual level. Applying national level cultural constructs at the individual level is justified since individuals espouse national cultures to different degrees [37]. While there is ample research on the impact of Asian culture in general and Korean culture in particular on human behavior and organizational issues, there is scant research on the influence of Asian culture in an organizational information security context.

The level of Self-construal of organizational users represents the individual relations to the group and the degree to which a team member is loyal to the group [40]. In a more individualistic society, the relationships among team members are less structured than in collectivistic environments. Members of a collectivist society have more cohesive relationships and are more likely to show loyalty. We use self-construal [35] to measure collectivism because in Korea, in-group collectivism is high, while competition with the outergroups is paramount. It is likely that a user in a Korean organization will engage in an illicit act to "win" against an outer-group competitor as much as to support the needs of the in-group. Measuring selfconstrual as a proxy for collectivism enables us to differentiate between relational collectivism and workrelated desire to follow organizational norms common in Korea.

Rather than differentiate between horizontal and vertical collectivism [34, 39], we measured the perceived power distance of the respondents. PD is used as a measure of power differential between leaders and followers. PD indicates the awareness of group members with unequally distributed power. In large PD groups, people perceive their supervisors as a "different kind of people" Filial piety or hyodo in Korean is considered a fundamental virtue. Similarly, in the workplace, subordinates are expected to have respect for their manager. It is considered a virtue not to speak about a manager's mistake publicly even when their decisions are wrong. Therefore, users might engage in illicit behavior if they are asked to by managers, or to protect a manager or a senior person. In this study, we define PD as users' relationships with their superiors (supervisors, managers) [32].

The last dimension we selected is LTO, which focuses on the temporal orientation of most people in a. High LTO individuals value the past and the future rather than actions important only for their effects on the here and now [1]. This tendency is often shown in Asian society and is termed Confucian Dynamism. Confucian ethics stress the importance of relationships and suitable attitudes necessary to maintain these relationships [28]. Individuals with high LTO scores are more attune to group harmony, ordering relationships by status and observing this order. The ordering relationship is similar to the one suggested by PD, but not identical. While ordering is accepted in high PD cultures, it does not imply the existence of respect towards seniors. Confucianism implies reverence and respect for. For example, elder team members would try to explain and teach their juniors since those are considered virtues. Younger members would admire the elders' opinions because of respect for social order. In addition, users with high LTO scores have a sense of tradition, which means sensitivity to saving face. Since, Korea's culture is rooted in Confucianism. harmony and face rather than rational work-performance influence work ethics [21]. Figure 1 depicts the proposed research model.

\section{Research model and hypotheses}

\section{development}

\subsection{IS misuse intention}

IS misuse intention measures a user's inclination to engage in IS misuse as suggested by D'Arcy, Hovav and Galletta [5]. In this study, we focus on five IS misuse scenarios: leakage of organizational information, use of unlicensed (pirated) software, password-sharing, use of external device and staying logged on to the system when the user is away. These five types of IS misuse are by no means an exhaustive list. Four of the scenarios were found to be major 
concerns for organizations [36], while the fifth (use of pirated software) is a common occurrence in Asia and is often considered an accepted behavior.

\subsection{Formal and informal sanctions}

Deterrence theory predicts that the greater the certainty and severity of formal sanctions for an illicit act, the more individuals are deterred from that act [5]. As such, formal sanctions can exert coercive pressure on users. Prior research found that in Korea, only the certainty of sanctions influence misuse intention [14]. Given that Korean users may perform an illicit act to save their face or maintain harmony, we do not expect that the existence of formal sanctions would reduce misuse intentions.

Hypothesis 1a: In Korea, perceived formal sanctions will not have a negative association with IS misuse intention.

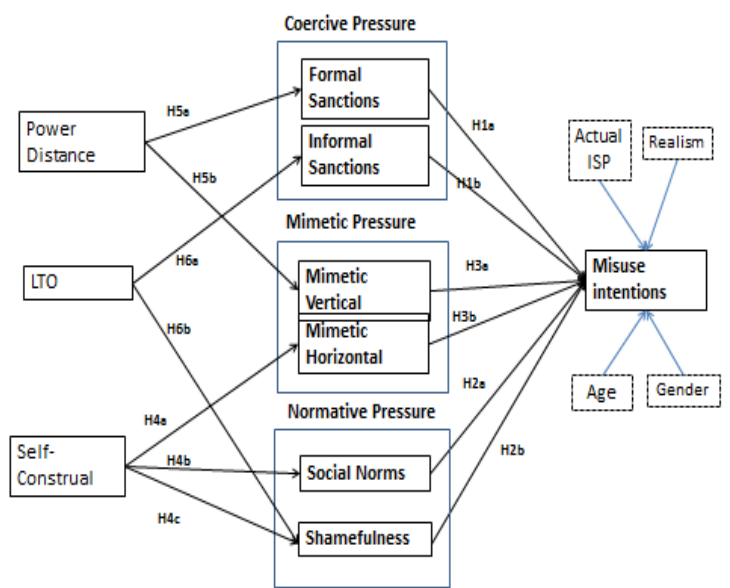

Figure 1. Research model

In addition to formal sanctions, informal sanctions can act as disincentives for policy violations [41]. Informal sanctions are often defined as implied social penalties for unacceptable behavior and may include disapproval [29], or embarrassment [8]. As such, informal sanctions could exert coercive pressure on users. In this study, we define informal sanctions in general terms since the interpretation may differ across cultures. Informal sanctions were found to reduce intention to commit white-collar crimes [29] and intentions to violate information security policies [41]. Given the need to maintain harmonious relationships with peers and managers, we propose that informal sanctions will coerce Korean users to reduce misuse intentions.
Hypothesis 1b: In Korea, informal sanctions will have a negative association with IS misuse intention.

\subsection{Norms and shamefulness pressures}

User behavior is often influenced by normative pressure of one's referent group. Social, organizational or group norms might supersede utilitarian considerations in some cultures. For example, normative pressure is likely to have significantly stronger influence on the adoption decisions of organizations in Korea than economic or technical considerations [15]. In collectivistic cultures, users are more concern with group norms and harmony and less with their own reward. For the purpose of this study, normative pressure is defined as the extent to which a particular IS misuse behavior is unacceptable to the users' referent group (colleagues, manager, friends). We suggest that when users in Korea perceive a given misuse behavior to be contrary to the norm, they are unlikely to engage in such a behavior.

Hypothesis 2a: In Korea, perceived normative pressure has a negative association with IS misuse intention.

The conceptualization of shame varies by culture. In Asian countries, shame is often equated with loss of face. Unlike guilt, which is internal and determined by the person's internal moral compass, face is social and is determined by the social structure of the individual. Face also depends on others knowledge of one's actions. Face is lost when an individual does not meet predetermined social requirements. Loss of face extends to the person's entire social structure [21]. Specifically, any unacceptable act by a user would result in the loss of face of his manager, teammates and the organization as a whole. Hence, we suggest that users in Korea will avoid shameful behavior.

Hypothesis 2b: In Korea, perceived shamefulness regarding an illicit behavior has a negative association with IS misuse intention.

\subsection{Mimetic pressure}

In this study, we measured two types of mimetics: vertical and horizontal. Institutional theory at the organizational level suggests that firms imitate successful competitors or other firms in their ecosystem [7]. Similarly, we expect that users in an organization will mimic successful users in the organization. Specifically, if users are aware that others have successfully circumvented organizational security policies or misused computing resources, they are 
more likely to engage in such behavior. We termed this phenomenon horizontal mimetics. Given the Korean culture, we expect that Korean users are likely to imitate successful misuse behavior.

Hypothesis 3a: In Korea, perceived horizontal mimetics regarding an illicit behavior has a positive association with IS misuse intention.

Vertical mimetic pressure is measured by users' perceptions of their supervisors and managers' misuse behavior [33]. In this study, we use perceived management participation [17] to measure vertical mimetics. However, we posit a different effect of management conduct on employees in Korea than was found in [17]. Kim [20: 3] describes the Koreans' legal consciousness as: "Historically, a common sentiment throughout Korea was that to obey the law implied the forfeiture of a reward that could be reaped through lawless or quasi-lawless behavior." While in Western societies, obeying the law is virtuous, the gap between law and virtue or morality is rooted in Korea's cultural and political history. The biased interpretation of the law based on social hierarchy results in a perceptional gap between the written law and its application in daily life [20].

Hypothesis 3b: In Korea, perceived vertical mimetic forces regarding an illicit behavior has a positive association with IS misuse intention.

\subsection{Cultural traits}

In Korea, collectivism often refers to one's in-group. While maintaining harmonious relationships with one's in-group are paramount, non-members of the ingroup are invisible and often ignored [3]. Given the Korean culture, we expect that espoused self-construal traits will increase an individual's perceived normative pressure as they try to maintain group harmony. Specifically, we expect individuals who are concerned with the group feel more shameful when engaging in unacceptable behavior. Similarly, self-construal persons are more likely to be sensitive to group norms.

Hypothesis 4a: In Korea, perceived self-construal behavior has a positive association with normative pressure.

Hypothesis 4b: In Korea, perceived self-construal behavior has a positive association with shamefulness.

Conversely, perceive self-construal behavior is likely to have a negative influence on horizontal mimetic pressure. Individualistic persons might try to imitate successful illicit behavior as they expect some personal gain from the imitation. However, selfconstrual persons are likely to consider the good of the group and forgo such imitations.
Hypothesis 4c: In Korea, perceived self-construal behavior has a negative association to horizontal mimetic pressure.

In this study, we define PD as users' relationships with their superiors [32]. High PD environments assume that managers make all decisions and employees are not to question these decisions. Preserving the face of elders is also a salient aspect of high PD cultures, as younger people are more reverent to superiors based on their acceptance of PD. Therefore, when employees perceive a high power distance in an organization, they are more likely to accept the formal sanctions imposed by their superiors.

Hypothesis 5a: In Korea, perceived high PD has a positive association with coercive pressure in the form of formal sanctions.

As mentioned above, vertical mimetic is measured by users' perceptions of their supervisors and managers' attitude towards information security and adherence to security policies. When users perceive high PD, they are less likely to question their managers' behavior. Hence, we posit that high PD will increase vertical mimetic perceptions.

Hypothesis 5b: In Korea, perceived high PD has a positive association with vertical mimetic pressure.

Individuals with high LTO scores are more attune to the attitudes required to maintain group harmony. In addition, users with high LTO scores have a heighten sense of tradition. Therefore, it is likely that users with high LTO are more sensitive to informal sanctions such as disapproval [29] or embarrassment [8].

Hypothesis 6a: In Korea, perceived high LTO has a positive association with informal sanctions.

Additionally, users with high LTO scores have higher sensitivity to saving face [13] and are more likely to be concerned with losing face than users with low LTO. Therefore, we assume that high LTO will increase shamefulness.

Hypothesis 6b: In Korea, perceived high LTO has a positive association with shamefulness.

\subsection{Control variables}

Following prior studies, we include age and gender as control variables. We also controlled for realism as suggested by Vance and Siponen [41]. We expect that users' perceived realism is likely to increase respondents' misuse intention. In addition, we controlled for the respondents' awareness of the existence of an organizational policy related to the particular misuse behavior presented in the assigned vignette. 


\section{Methodology and results}

This study uses a survey instrument containing five IS misuse scenarios. Each respondent received only one of the five scenarios. We use the randomization feature available in Qualtrics to assign the surveys for online responders and a manual randomization for offline responders. Following each scenario, respondents are presented with a series of questions designed to measure their perceptions regarding the behavior depicted in the scenario. In addition, the survey measured individual cultural traits (Appendix A). The questionnaires were distributed to responders at a medium-size IT company and a major university hospital. In addition, the survey was administered to MBA students at a major university in Korea. The combined sample size contained 232 usable surveys. $20.6 \%$ of the respondents were hospital and health workers, $22.4 \%$ of responses came from the mid-size IT company and $45.8 \%$ of the responses came from MBA students. The remaining $11.2 \%$ of the surveys were completed by project managers at a large Chaebol. Since the sample was mostly a convenience sample, the response rate from the hospital, MBA students and project managers was close to $100 \%$. The response rate attributed to the IT Company was only $50 \%$. This low response rate was primarily because we used the mid-size IT company to run our pilot test (the pilot data is not included here). Subsequently, we asked that respondents to the pilot would not participate in the actual survey.

\begin{tabular}{|c|c|c|c|}
\hline & AVE & CR & $\begin{array}{c}\text { Cronbach' } \\
\text { S Alpha }\end{array}$ \\
\hline Misuse & 0.9096 & 0.9526 & 0.9006 \\
\hline $\begin{array}{c}\text { Formal } \\
\text { sanctions }\end{array}$ & 0.6992 & 0.9025 & 0.8604 \\
\hline $\begin{array}{c}\text { Informal } \\
\text { sanctions }\end{array}$ & 0.5592 & 0.8353 & 0.7380 \\
\hline Norms & 0.8277 & 0.9350 & 0.8951 \\
\hline $\begin{array}{c}\text { Shamefuln } \\
\text { ess }\end{array}$ & 0.7911 & 0.9378 & 0.9112 \\
\hline $\begin{array}{c}\text { Horizontal } \\
\text { mimetic }\end{array}$ & 0.9304 & 0.9639 & 0.9252 \\
\hline $\begin{array}{c}\text { Vertical } \\
\text { mimetic }\end{array}$ & 0.7253 & 0.9294 & 0.9083 \\
\hline PDI & 0.6258 & 0.8684 & 0.8324 \\
\hline LTO & 0.6698 & 0.8898 & 0.8657 \\
\hline $\begin{array}{c}\text { Self- } \\
\text { construal }\end{array}$ & 0.6308 & 0.8947 & 0.8530 \\
\hline
\end{tabular}

Table 1.
We report both the construct composite reliability (CR) and Cronbach's alpha. CR value of 0.6 is regarded as an acceptable level. Convergent validity was assessed by calculating the average variance extracted (AVE). AVE score of 0.5 is commonly acceptable and a score of 0.7 is recommended for a reliable construct. The $\mathrm{CR}$ and AVE values of all constructs exceed the minimum acceptable level and demonstrate appropriate reliability and convergent validity of all constructs (Table 1). The square root of AVE for each construct is larger than the correlation of the construct with any other constructs thus confirming discriminant validity. To assess the common method bias, we performed a Harman single-factor test [31]. The test results show nine factors with Eigen value larger than 1 . The highest covariance explained by one factor is 11.698 and the cumulative covariance of $29.996 \%$ is lower than $50 \%$ suggesting that common method bias is not substantial in this study.

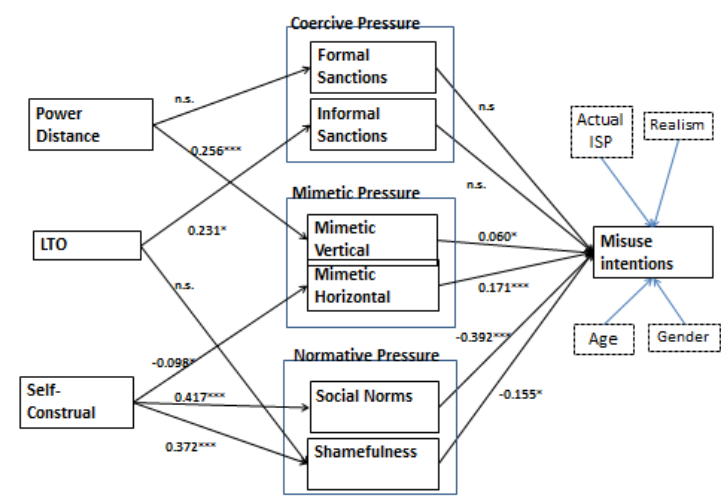

Figure 2. Path analysis results ( ${ }^{*} P<0.1$; $\left.{ }^{\star \star} P<0.05 ;{ }^{\star \star \star} P<0.001\right)$

Additionally, all items have higher loadings with their respective construct than with any other construct. To measure the research model, we used Smart PLS 2.0. The results are shown in Figure 2 and Appendic B. Our model explains $46.8 \%$ of the dependent variable. We hypothesized that formal sanctions will have no effect on misuse behavior. Indeed the path co-efficient between formal sanctions and misuse intention is not significant. Albeit this result does not support our hypothesis, it also does not contradict it. As predicted, norms and shamefulness reduce misuse intention (supporting $\mathrm{H} 2 \mathrm{a}$ and $\mathrm{H} 2 \mathrm{~b}$ ), while horizontal mimetics increases misuse intentions (supporting H3a). Vertical mimetics have a positive effect on misuse intention $(p<0.10)$, marginally supporting H3b. Contradictory to our expectations, coercive pressure in the form of informal sanctions had no effect on misuse intention (rejecting H1b). As hypothesized, PD positively 
influenced vertical mimetics (supporting H5b). However, PD had no effect on formal sanctions (rejecting H5a). LTO increases informal sanction perceptions $(\mathrm{p}<0.10)$ (marginally supporting H6a) but had no effect on shamefulness (rejecting H6b). Selfconstrual positively effects norms and shamefulness (supporting $\mathrm{H} 4 \mathrm{~b}$ and $\mathrm{H} 4 \mathrm{c}$ ) and negatively effects horizontal mimetics $(\mathrm{p}<0.10)$ (marginally supporting $\mathrm{H} 4 \mathrm{a})$. For the control variables, existence of a security policy was found to reduce misuse intention, while realism of the scenario to increase misuse intention. Older Koreans are less likely to engage in misuse. Gender had no influence on misuse intention.

\section{Discussion}

The goal of this study is to examine the influence of institutional pressure at the individual level on misuse behavior in a non-Western culture. We chose Asia as our target population since in Asian culture, norms, social pressure and structure supersede individual or rational choice. Our results support the above assertion. Normative pressure in the form of social norms and shamefulness reduce misuse intention. However, the effect of shamefulness on misuse intention is only marginal. This could be due to the general definition used for shamefulness. In our attempt to create a universal scale (to be used later for a cross-cultural investigation), we adapted our questions from [9]. It is possible that a more specific questions regarding loss of face would have yield different results.

Coercive pressure in the form of formal and informal sanctions had no effect on misuse behavior. These results indicate that in Korea, the threat of punishment is less important than normative or mimetic pressures. However, we expected informal sanctions to reduce misuse intention since Asian culture emphasizes the severity of sanctions imposed by ones' social structure. It is possible that the scenarios presented in this study are not considered illicit and thus users do not expect a reprimand from their social network. Alternatively, [34]: 244 states: "For example, East Asians avoid confrontation and would rather tell a lie than cause anyone to lose face." Therefore, it is possible that choosing to engage in an illicit behavior to maintain group harmony and face will not result in social reprimand.

Similarly, mimetic pressure in the form of peer (horizontal pressure) and management (vertical pressure) also influenced misuse intention. As expected, when users realize that others have successfully engaged in illicit behavior and succeeded, they are more likely to follow suit. The effect of vertical mimetic was not as strong as that of horizontal mimetic. Emulating the illicit behavior of a peer is an acceptable norm, especially if the illicit behavior ensures team harmony. However, as the perceptional gap between the written law and its application may be shrinking [20], imitating the illicit behavior of a supervisor or a manager is not always acceptable since seniors have more flexibility in their interpretation of laws and policies [14].

As to the espoused cultural traits, as expected, selfconstrual had a significant effect on social norms and shamefulness. Users who care about the good of the group are more likely to be influenced by social norms and shame. Thus, we conclude that collectivistic workbehavior reduces misuse intention via social norms and shame. Confucian dynamism had a positive influence on informal sanctions. However, Confucian dynamism had no influence on shamefulness. As mentioned above, this could be due to our definition of shame (rather than face). Thus, we conclude that in the context of this study, LTO has no effect on misuse intention. PD had no influence on formal sanctions but had a positive effect on vertical mimetic pressure. These results suggest that the higher the power distance between employees and their superiors, the more cognizant the employees are to the managers' priorities, goals and behavior.

\section{Implications to theory and practice}

This study contributes to our body of knowledge in several ways. Although prior research examined antecedents to misuse behavior, the use of institutional pressure on such behavior in a non-Western context is novel. Our results show that in Asian culture, sanctions are ineffective while normative pressure is effective. In addition, investigating mimetics as an enabler is also unique. Most existing misuse studies look for inhibitors of illicit behavior or for a rational costbenefit balance. Our examination of mimetic behavior suggests the existence of environmental factors than encourage users to engage in misuse behavior. In addition, we measured the most prevalent espoused cultural values in Korea and their influence on institutional pressure. By understanding the underlying process by which espoused cultural values and institutional pressure affect misuse intention, the results provide evidence that the intention of "rational" users could be affected by their normative and social environment and espoused cultural values.

From a practical perspective, managers of Asian or global organizations should acknowledge the need to create an institutional environment that recognizes misuse behavior as a social phenomenon. Specifically, 
organizations need to encourage a normative environment that discourages misuse behavior. Therefore, organizations should highlight proactive management commitment to cyber security compliance. For example, organizations can publish use-cases of positive employees and managers' behavior.

\section{Limitations and future research}

As most research papers, some limitations should be considered. In calling attention to the potential limitations, we simultaneously offer suggestions for future research. First, this is a single country study. As such, the results are not generalizable to other countries or cultures. Future research can examine cross-cultural institutional influence on misuse intention. The study did not differentiate between the severity and likelihood of the various misuse scenarios. Our goal was to examine misuse behavior in general rather than for a specific behavior. In addition, the study was limited to five scenarios. Future research can examine a different set of scenarios and the differentiating effect of various types of scenarios. In an attempt to create a comprehensive scale, we used a general definition of shamefulness. This definition might not be fully applicable in the Korean context since Koreans are mostly concerned with saving face. Future research should examine the conceptualization of norms in various cultural contexts in more detail. Furthermore, the limited effect of informal sanctions and shamefulness on misuse intention suggests the need for a deeper understanding of what is considered illicit behavior in Western culture and virtuous behavior in Asian culture. Finally, we used espoused cultural traits as antecedents to institutional pressure. We recognize the existence of numerous theoretically founded factors that can affect institutional pressure. For example, can training and education increase normative pressure and reduce negative mimetic pressure? Can individual characteristics moderate the effect of institutional pressure on misuse? What are the relationships between organizational culture, structure or leadership on institutional pressure?

\section{References}

[1]. Bearden, W.O., Money, R. B., and Nevins, J. L. (2006). "A Measure of Long-Term Orientation: Development and Validation," Journal of the Academy of Marketing Science 34(3):456-467.

[2]. Bévort, F. and Suddaby, R. (2016). Scripting professional identities: How individuals make sense of contradictory institutional logics. Journal of Professions and Organization, 3(1), 17-38.

[3]. Cho, Y.-H. and J. Yoon (2001). "The Origin and Function of Dynamic Collectivism: An Analysis of Korean Corporate Culture.” Asia Pacific Business Review 7(4):70-88.

[4]. Choe, J.-M. (2004). "The consideration of cultural differences in the design of information systems." Information \& Management 51(5):669-684.

[5]. D’Arcy, J., Hovav, A., Galletta, D. (2009) User awareness of security countermeasures and its impact on information systems misuse: A deterrence perspective, Information Systems Research 20(1):79-98.

[6]. Dash, M., Bhusan, P.B., and Samal, S. (2014). "Determinants of Customers' Adoption of Mobile Banking: An Empirical Study by Integrating Diffusion of Innovation with Attitude." Journal of Internet Banking and Commerce, 19(2):2-21.

[7]. DiMaggio, P. J. and Powell, W. W. (1983). "The iron cage revisited: Institutional isomorphism and collective rationality in organizational fields." American Sociological Review. 48(2):147-160.

[8]. Grasmick, H., R. Bursik, Kinsey, K. (1991). "Shame and Embarrassment as Deterrents to Noncompliance with the Law: The Case of an Antilittering Campaign." Environment and Behavior 23(2):233-251.

[9]. Grasmick, H., Kobayashi, E. (2002). "Workplace deviance in japan: applying an extended model of deterrence." Deviant Behavior: An Interdisciplinary Journal, 23:21-43.

[10]. Guo, K.H., Yuan, Y., Norman P., Connelly, A. and Connelly, C.E (2011). "Understanding Nonmalicious Security Violations in the Workplace: A Composite Behavior Model. Journal of Management Information Systems. 28(2):203-236.

[11]. Creed, W. D., De Jordy, R., and Lok, J. (2010) "Being the Change: Resolving Institutional Contradiction Through Identity Work', Academy of Management Journal, 53:133664.

[12]. Herath, T., and Rao, H.R., (2009) "Protection Motivation and Deterrence: A Framework for Security Policy Compliance in Organisations", European Journal of Information Systems, 18(2):106-125.

[13]. Hofstede G., Culture's consequences: Comparing values, behaviors, and organizations across nations, Second edition, Sage Publications, Thousand Oaks, CA, 2001.

[14]. Hovav, A. and D'Arcy, J. (2012) “Applying an Extended Model of Deterrence across Cultures: An Investigation of Information Systems Misuse in the U.S. and South Korea." Information \& Management. 49(2):99-110.

[15]. Hovav, A., Hemmert, M and Kim, Y-J. (2011) "Determinants of Internet Standards Adoption: The Case of South Korea." Research Policy 40(2):253-262.

[16] Hovav, A., and Putri, F. F. (2016) "This is My Device! Why Should I Follow Your Rules? Employees' Compliance with BYOD Security Policy." Pervasive and Mobile Computing.

http://dx.doi.org/10.1016/j.pmcj.2016.06.007 
[17]. Hu, Q., Xu, Z., Dinev, T., and Ling, H.(2011). "Does deterrence work in reducing information security policy abuse by employees?" Communications of the ACM, 54(6):54-60.

[18]. Johnston, A.C., and Warkentin, M. (2010)."Fear Appeals and Information Security Behaviors: An Empirical Study." MIS Quarterly, 34(3):549-566.

[19] Johnston, A. C., Warkentin, M., \& Siponen, M. (2015). An enhanced fear appeal rhetorical framework: Leveraging threats to the human asset through sanctioning rhetoric. MIS Quarterly, 39(1), 113-134. Willison, R. and Warkentin, M. (2013). "Beyond deterrence: An expanded view of employee computer abuse.” MIS Quarterly. 37(1):1-20.

[20]. Kim, C.J., (2000). "Korean attitude towards law." Pacific Rim Law \& Policy Journal. 10(1):1-46.

[21]. Kim, J.Y., Nam, S.H. (1998) "The concept and dynamics of face: Implications for organizational behavior in Asia." Organization Science 9(4):522-534.

[22]. Lewis, W., R. Agarwal, V. Sambamurthy, V. (2003). "Sources of influence on beliefs about information technology use: An empirical study of knowledge workers." MIS Quarterly: 27(4):657-678.

[23]. Lok, J. (2010) "Institutional Logics as Identity Projects." The Academy of Management Journal, 53(6):1305-1335.

[24] Lowry, P. B., Posey, C., Bennett, R. J. and Roberts, T L. (2015). Leveraging fairness and reactance theories to deter reactive computer abuse following enhanced organisational information security policies: An empirical study of the influence of counterfactual reasoning and organisational trust, Information Systems Journal, 25(3): 193-230.

[25]. Marett, K., Otondo, R.F., and Taylor G.S. (2013) "Assessing the effects of benefits and institutional influences on the continued use of environmentally munificent bypass systems in long-haul trucking." MIS Quarterly, 37(4):13011312.

[26]. Meyer, J. W. and Rowan, B. (1977). "Institutionalized organizations: Formal structure as myth and ceremony." American Journal of Sociology: 340-363.

[27]. OECD (2014).

https://stats.oecd.org/Index.aspx?DataSetCode=ANHRS

[28]. Park, H., M. T. Rehg, et al. (2005). "The Influence of Confucian Ethics and Collectivism on Whistleblowing Intentions: A Study of South Korean Public Employees." Journal of Business Ethics 58:387-403.

[29]. Paternoster, R. and Simpson, S. (1996)“ Sanction Threats and Appeals to Morality: Testing a Rational Choice Model of Corporate Crime." Law \& Society Review. 30(3):549-584.

[30]. Phang, C.W., Kankanhalli, A. Ang, C. (2008) "Investigating organizational learning in eGovernment projects: A multi-theoretic approach." The Journal of Strategic Information Systems. 17(2): 99-123

[31] Podsakoff P.M, and Organ D. W. (1986). "Self-reports in organizational research: problems and prospects." Journal of Management. 12(4):531-544.
[32]. Sharma, P. (2010). "Measuring personal cultural orientations: scale development and validation." J. of the Academy of Marketing Science. 38:787-806.

[33]. Sharma, R., and Yetton, P. (2003). "The Contingent Effects of Management Support and Task Interdependence on Successful Information Systems Implementation.” MIS Quarterly, 27(4):533-556.

[34]. Singelis, T.M., Triandis, H.C., Bhawuk, D.P.S., and Gelfand, M.J. (1995). "Horizontal and Vertical Dimensions of Individualism and Collectivism: A Theoretical and Measurement Refinement," Cross-Cultural Research 29(3):240-275.

[35]. Singelis, T. M. (1994). The measurement of independent and interdependent self-construals. Personality \& Social Psychology Bulletin, 20(5):580-591.

[36]. Siponen, M. and A. Vance (2010). "Neutralization: New Insights into the Problem of Employee Information Systems Security Policy Violations.” MIS Quarterly 34(3): 487-502.

[37]. Srite, M., Karahanna, E. (2006). "The role of espoused national cultural values in technology acceptance." MIS Quarterly 30(3):679-704.

[38]. Tolbert, P. S. and Zucker, L. G. (1999). "The institutionalization of institutional theory." Studying Organization: Theory \& Method: 169-184.

[39]. Triandis, H. C. (1995). Individualism and collectivism. Boulder, CO: Westview Press.

[40]. Triandis, H. C. and M. J. Gelfand (1998). "Converging Measurement of Horizontal and Vertical Individualism and Collectivism." Journal of Personality and Social Psychology 74(1):118-128.

[41]. Vance, A. and Siponen, M. (2012) "IS Security Policy Violations: A Rational Choice Perspective" Journal of Organizational and End User Computing, 24(1).

[42]. Willison, R. and Warkentin, M. (2013). "Beyond deterrence: An expanded view of employee computer abuse." MIS Quarterly. 37(1):1-20.

\section{APPENDIX A: Scales}

INT, formal sanctions (PC and PS) measures were adapted from D'Arcy et al (2009). Below are the newly developed scales used in this study:

Coercive Pressure (informal sanctions)

If you <engaged in the behavior described in the scenario>, you would lose the respect and good opinion of your close friends and family.

If you <ditto>, you would lose the respect and good opinion of your close friends and family.

Losing the respect and good opinion of your close friends and family for <ditto> would create a problem in your life.

Losing the respect and good opinion of your coworkers for < ditto>would create a problem in your life. Normative Pressure (subjective norms)(adapted from Herath and Rao, 2009a) 
If you $\langle$ ditto $\rangle$, your co-workers would disapprove. If you $\langle$ ditto $\rangle$, your supervisor would disapprove.

If you <ditto>, your top management would disapprove.

Shame (adapted from Grasmick and Kobayashi, 2002). How shameful would you feel if you <ditto>.

How shameful would you feel if your close friends and family knew that you <ditto>.

How shameful would you feel if your co-workers knew that you <ditto>.

How much of a problem would it create in your life if you felt ashamed for <ditto>.

Mimetic horizontal (newly developed)

I am aware of employees in my organization who have $<$ ditto> and did not get caught.

I am aware of employees in my organization who have $<$ ditto> and did not get punished

Mimetic vertical (Adapted from $\mathrm{Hu}$ et al, 2012)

Senior management in my organization actively champions security goals.

Top management in my organization considers information security an important organizational priority.

Top managers in my organization adhere to security policies themselves.

My direct supervisor actively champions security goals. My direct supervisor considers information security an important organizational priority.

My direct supervisor adheres to security policies him/herself.

Self-construal (Adapted from Singelis 1994 and Gudykunst and Lee 2003)

Being accepted as a member of a group is more important than having autonomy.

Being loyal to a group is more important than individual gain.

Individual rewards are not as important as group welfare.

Being accepted as a member of a group is more important than independence.

Group success is more important than individual success.

It is more important for managers to encourage loyalty and a sense of duty in subordinates that it is to encourage individual initiative.

Power distance (Adapted from Sharma 2010)

I easily conform to the wishes of someone in a higher position than mine.

It is difficult for me to refuse a request if someone senior asks me.

I tend to follow orders without asking questions.

I find it hard to disagree with authority figures.
LTO (Confucian work dynamism adapted from Vitell et al., 2003)

I am always careful to avoid doing what is improper.

I avoid offending others.

I feel guilty if I behave improperly.

I honor and respect the elderly.

APPENDIX B: Path coefficients, betas and corresponding p-values

\begin{tabular}{|c|c|c|c|}
\hline Path & Beta & T-value & P-value \\
\hline $\begin{array}{l}\text { Formal sanctions } \\
->\text { Misuse }\end{array}$ & 0.070 & 0.917 & n.s. \\
\hline $\begin{array}{l}\text { informal } \\
\text { Sanctions } \quad-> \\
\text { Misuse }\end{array}$ & 0.059 & 0.672 & n.s. \\
\hline Norms -> Misuse & -0.392 & 4.802 & $P<0.001$ \\
\hline $\begin{array}{l}\text { Shamefulness -> } \\
\text { Misuse }\end{array}$ & -0.155 & 1.624 & $P=0.052$ \\
\hline $\begin{array}{l}\text { Vertical mimetic } \\
->\text { Misuse }\end{array}$ & 0.060 & 1.006 & $P<0.10$ \\
\hline $\begin{array}{l}\text { Horizontal } \\
\text { mimetic } \quad-> \\
\text { Misuse }\end{array}$ & 0.171 & 2.973 & $P<0.01$ \\
\hline $\begin{array}{l}\text { PDI -> Formal } \\
\text { sanctions }\end{array}$ & -0.074 & 0.764 & n.s. \\
\hline $\begin{array}{l}\text { PDI -> Vertical } \\
\text { Mimetic }\end{array}$ & 0.256 & 3.530 & $P<0.001$ \\
\hline $\begin{array}{l}\text { Self-construal } \quad-> \\
\text { Norms }\end{array}$ & 0.417 & 7.577 & $P<0.001$ \\
\hline $\begin{array}{l}\text { Self-construal -> } \\
\text { Horizontal } \\
\text { mimetic }\end{array}$ & -0.098 & 1.456 & $P<0.10$ \\
\hline $\begin{array}{l}\text { Self-construal } \quad-> \\
\text { Shame }\end{array}$ & 0.372 & 5.433 & $P<0.001$ \\
\hline $\begin{array}{l}\text { LTO -> informal } \\
\text { Sanctions }\end{array}$ & 0.231 & 2.154 & $P<0.05$ \\
\hline LTO -> Shame & -0.078 & 1.180 & n.s. \\
\hline Policy -> Misuse & -0.150 & 2.215 & $P<0.05$ \\
\hline Age & -0.167 & 3.486 & $P<0.001$ \\
\hline Gender & 0.041 & 0.821 & n.s. \\
\hline Realism & 0.193 & 3.184 & $P<0.001$ \\
\hline
\end{tabular}

